\title{
Control of diabetes mellitus in the Eastern province of Saudi Arabia: results of screening campaign
}

\author{
N.A. Al-Baghli, ${ }^{7}$ K.A. Al-Turki, A.J. Al-Ghamdi, A.G. El-Zubaier, ${ }^{7}$ M.M. Al-Ameer ${ }^{3}$ and F.A. Al-Baghli ${ }^{3}$
}

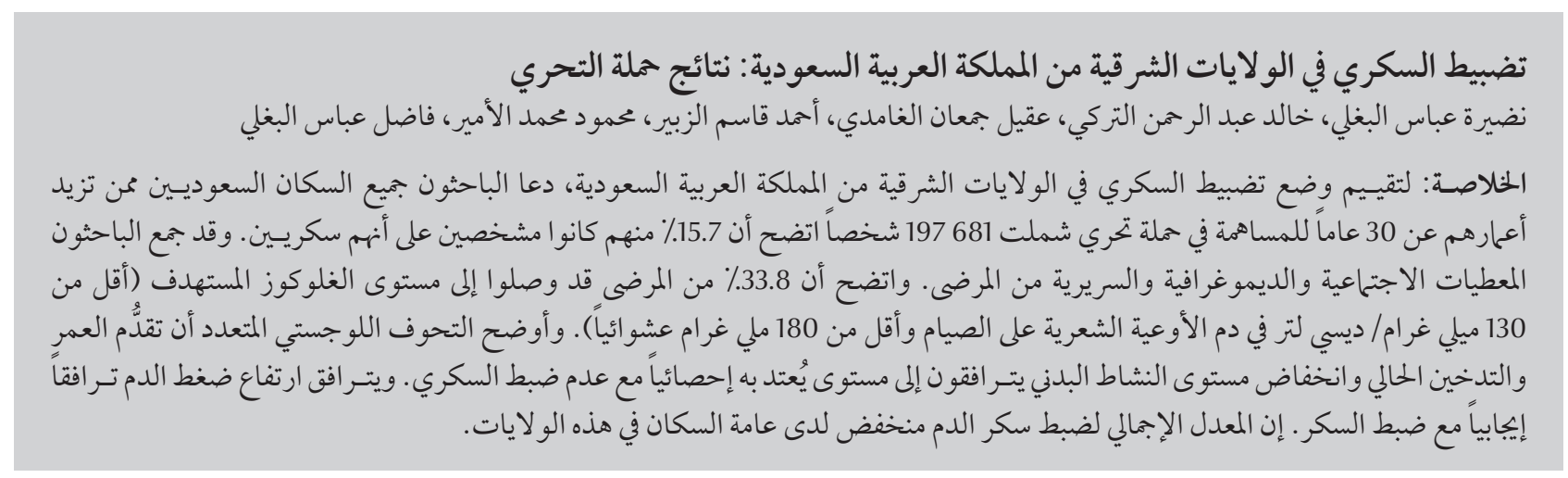

ABSTRACT To assess the status of diabetes mellitus (DM) control in the Eastern province of Saudi Arabia, all Saudi Arabian residents aged 30 years and above were invited to participate in a screening campaign. Of 197681 participants screened 15.7\% had a previous diagnosis of DM. Sociodemographic and clinical data were collected from these patients. Only 33.8\% of patients were achieving their glycaemic control target (fasting or random capillary blood glucose $<130 \mathrm{mg} / \mathrm{dL}$ or $<180 \mathrm{mg} / \mathrm{dL}$ respectively). Multiple logistic regression analysis showed that higher age, current smoking and lower level of physical activity were significantly associated with uncontrolled DM. Hypertension was positively associated with glycaemic control. The overall rate of diabetes control is unacceptably low in the general population of this province.

\section{Contrôle du diabète sucré dans la province orientale d'Arabie saoudite : résultats de la campagne de dépistage}

RÉSUMÉ En vue d'évaluer l'état de la lutte contre le diabète sucré dans la province orientale de l'Arabie saoudite, tous les habitants âgés de 30 ans et plus ont été invités à participer à une campagne de dépistage. Sur les 197681 personnes dépistées, 15,7 \% présentaient un diagnostic antérieur de diabète sucré. Les données sociodémographiques et cliniques de ces patients ont été recueillies. Seuls 33,8 \% d'entre eux atteignaient leur objectif de contrôle glycémique (glycémie à jeun ou glycémie aléatoire dans le sang capillaire $<130 \mathrm{mg} / \mathrm{dl}$ ou $<180 \mathrm{mg} / \mathrm{dl}$, respectivement). Une analyse de régression logistique multiple a montré qu'un âge avancé, le tabagisme au moment de l'étude et une faible activité physique étaient significativement associés à un diabète sucré non contrôlé. Une corrélation positive a également été observée entre hypertension artérielle et contrôle glycémique. La faiblesse du taux global de contrôle du diabète au sein de la population de cette province en général n'est pas acceptable.

'Directorate of Health Affairs, Ministry of Health, Dammam, Saudi Arabia (Correspondence to N.A. Al-Baghli: nadiraa@windowslive.com). ${ }^{2}$ College of Medicine, King Faisal University, Dammam, Saudi Arabia.

${ }^{3}$ Al-Amel Complex of Mental Health, Riyadh, Saudi Arabia.

Received: 04/06/08; accepted: 22/07/08 


\section{Introduction}

Diabetes mellitus (DM) is accompanied by long-term microvascular, neurological and macrovascular complications [1]. Glycaemic control is fundamental to the management of diabetes. The United Kingdom Prospective Diabetes Study (UKPDS) [2,3] and other randomized controlled trials [4] have demonstrated the effectiveness of good control of DM in the reduction of clinically important retinopathy, including vision-threatening lesions, and of nephropathy and neuropathy. Meta-analysis of the evidence similarly supports the potential of glycaemic control in reducing cardiovascular disease (CVD) [5]. Additional analysis indicates that therapy to achieve near normalization of blood glucose levels is cost effective compared with other treatments $[6,7]$.

On the other hand, it has been found that, while tight glycaemic control decreases the risk of microvascular complications, it carries the risk of developing hypoglycaemia and weight gain [8]. Hence the goal of therapy is to achieve blood glucose as close to normal as possible while avoiding hypoglycaemia.

The recent recommendations of the American Diabetes Association for glycaemic control targets in adults are a glycosylated haemoglobin (HbAlc) level $<7.0 \%$, pre-prandial capillary plasma glucose (CPG) $70-130 \mathrm{mg} /$ $\mathrm{dL}(3.9-7.2 \mathrm{mmol} / \mathrm{L})$ and a peak postprandial $\mathrm{CPG}<180 \mathrm{mg} / \mathrm{dL}(<10.0$ $\mathrm{mmol} / \mathrm{L})[9]$.

In Saudi Arabia, there is a scarcity of published epidemiological data on glycaemic control in DM and the factors associated with it. The aim of this study was to assess the pattern of follow-up and status of glycaemic control in patients with a previous diagnosis of DM according to their socidemographic and clinical risk factors.

\section{Methods}

This study was part of a larger screening campaign conducted in the Eastern province of Saudi Arabia between 28 August 2004 and 18 February 2005. The methodology has been described previously [10]. A scientific committee established the detailed procedures for the campaign, including the standards for running the campaign, validation of instruments and health education materials to be used, staff training, financial supervision and data processing and entry. A media campaign was organized in each health sector (district) of the province using written and audiovisual materials, and posters on billboards in the streets and other public places.

\section{Sample}

The target population was all Saudi Arabian residents of the Eastern province of Saudi Arabia, aged 30 years and above, excluding pregnant women (650 000 subjects). They were invited to participate in a screening campaign for the early detection of DM and hypertension by attending one of the $300+$ examination centres distributed in all primary health care centres, all government hospitals and most private hospitals and dispensaries, in addition to mobile teams in public venues.

The analysis described in this paper included only those participants who were previously diagnosed diabetics being managed by dietary methods or antidiabetic drugs; those who were newly diagnosed with DM during the campaign were excluded.

\section{Data collection}

A structured questionnaire for data collection was developed using information obtained from focus groups and was validated by experts in the fields of DM and hypertension. Specially trained members of health teams interviewed the participants and completed the questionnaire. Information was recorded about age, sex, place of residence, marital status, occupation, education, family income, physical activity and smoking. Current smoking was defined by subjects' self-reports as having ever smoked $>100$ cigarettes and currently smoking, every day or occasionally, for 1 month or more before the campaign any tobacco products including waterpipe (shisha). This group was compared with nonsmokers (ex- and never smokers). Physical activity at work or leisure was grouped into 4 categories: no physical activity (completely sedentary lifestyle, e.g. reading, watching TV); mild physical activity ( $<3$ hours per week, e.g. ordinary housework, walking), moderate exercise (3+ hours exercise per week, e.g. cycling or walking); and strenuous physical activity (5+ hours per week, e.g. jogging or swimming).

Clinical data were also obtained. Participants were asked if they had been previously diagnosed with DM and were being treated for high blood glucose and, if so, the place of treatment. The participants underwent measurements of weight, height, blood pressure and CPG. Body mass index (BMI) was calculated as weight in kilograms divided by height in metres squared. BMI $25.0-29.9 \mathrm{~kg} / \mathrm{m}^{2}$ was classified as overweight, $\mathrm{BMI} \geq 30.0 \mathrm{~kg} / \mathrm{m}^{2}$ as obese, and BMI $18.5-24.9 \mathrm{~kg} / \mathrm{m}^{2}$ as normal. Blood pressure (BP) was measured and hypertension was diagnosed based on the recommendations of the 7 th report of the Joint National Committee on Prevention, Detection, Evaluation, and Treatment of High Blood Pressure (JNC-VII) [11]. Whole blood glucose concentration was measured using a portable glucometer, based on reflectance photometry. Glycaemic control targets were defined as preprandial $\mathrm{CPG}<130 \mathrm{mg} / \mathrm{dL}$ after fasting for $>8$ hours or random postprandial CPG $<180 \mathrm{mg} / \mathrm{dL}$. Patients with CPG levels above those readings were defined as having uncontrolled glycaemia. Family 
history of DM and personal history of CVD were also recorded.

Coordinators were assigned for each sector to supervise the examination centres, to ensure all forms were completed, to follow up defaulters and to liaise with coordinators in other health sectors and the main supervision committees. The forms were collected from each sector and were double-checked for completeness. Ineligible people were excluded and forms with incomplete data or unconfirmed results were sent back to the health sectors with a covering letter for corrections to be made.

The participants were assured of the confidentiality of the information collected, after explaining the purpose of the campaign. In addition, health education materials were distributed to high-risk groups.

\section{Data analysis}

The differences between previously diagnosed diabetics with controlled and uncontrolled glycaemia were assessed using analysis of variance (ANOVA). The chi-squared test was used to assess the relationship between glycaemic control and socioeconomic and clinical risk factors. Cardiovascular risk factors found to be associated with uncontrolled DM were included in the multiple logistic regression and age and sex were included in the model. Age was treated as a continuous measure and the other variables as categorical measures. The odds ratios (ORs) and 95\% confidence intervals (CIs) were calculated. $P$ value $<0.05$ was considered statistically significant.

\section{Results}

\section{Prevalence of DM and patients' background characteristics}

Data were missing for 912 people (0.5\%) out of the total of 197681 participants in the campaign. The prevalence of previously diagnosed DM was $15.7 \%$ ( $n=30798$ ), constituting $30.4 \%$ of the target population. A higher proportion of the women were diagnosed with DM (16307, 16.9\%) than the men (14 486, $14.4 \%), P<0.001)$.

Among these previously diagnosed diabetics, $97.5 \%$ were receiving treatment through different health care facilities, most commonly Ministry of
Health (MOH) facilities (65.0\%), followed by other government hospitals (17.9\%) or private facilities (11.8\%), while $(2.8 \%)$ were treated in multiple health care facilities; for 1214 subjects the place of treatment was unknown.

CPG values were obtained for 30749 (99.8\%) of these patients with previously diagnosed DM. Of these, 10384 (33.8\%) were achieving the glycaemic control target. Random CPG was obtained for 22348 patients, $37.1 \%$ of whom had controlled glycaemia $(<180 \mathrm{mg} / \mathrm{dL})$. Fasting CPG level was obtained for 8401 patients and 24.9\% had controlled fasting CPG levels $(<130 \mathrm{mg} / \mathrm{dL})$.

Table 1 shows the mean fasting CPG and random CPG levels according to age and sex. In men the mean fasting CPG did not vary significantly with age, whereas random CPG increased with age and reached its peak in the age group $60-69$ years $(P<0.001)$. For women the fasting CPG levels increased significantly with age, peaking in the age group 50-59 years $(P<0.001)$, while random CPG reached its peak in the age group 60-69 years. Women in general had higher mean fasting CPG

\begin{tabular}{|c|c|c|c|c|c|c|}
\hline \multicolumn{7}{|c|}{$\begin{array}{l}\text { Table } 1 \text { Mean fasting and random capillary blood glucose (CBG) levels by age in men and women with previously diagnosed } \\
\text { diabetes mellitus }\end{array}$} \\
\hline Sex/age (years) & \multicolumn{2}{|r|}{ Mean (SD) } & $P$-value & \multicolumn{2}{|r|}{ Mean $(\mathrm{SD})$} & $P$-value \\
\hline \multicolumn{7}{|l|}{ Men } \\
\hline $30-39$ & 344 & $180.9(81.8)$ & \multirow[t]{6}{*}{0.265} & 1878 & $223.9(110.4)$ & \multirow[t]{6}{*}{$<0.001$} \\
\hline $40-49$ & 696 & $181.9(73.8)$ & & 3657 & $232.1(106.3)$ & \\
\hline $50-59$ & 701 & $183.8(74.3)$ & & 3059 & 236.4 (107.0) & \\
\hline $60-69$ & 703 & $185.2(77.6)$ & & 1941 & $240.4(105.7)$ & \\
\hline $70+$ & 394 & $174.8(73.2)$ & & 1005 & $239.1(108.1)$ & \\
\hline Total & 2838 & $182.1(75.8)$ & & 11540 & 233.9 (107.3) & \\
\hline \multicolumn{7}{|l|}{ Women } \\
\hline $30-39$ & 608 & $185.0(90.0)$ & \multirow[t]{6}{*}{$<0.001$} & 1868 & $213.1(106.6)$ & \multirow[t]{6}{*}{$<0.001$} \\
\hline $40-49$ & 1688 & $194.7(82.2)$ & & 3866 & $231.9(110.4)$ & \\
\hline $50-59$ & 1689 & $197.5(81.1)$ & & 2781 & $239.4(110.0)$ & \\
\hline $60-69$ & 1025 & $188.4(75.2)$ & & 1502 & 239.5 (107.5) & \\
\hline $70+$ & 508 & $183.4(77.6)$ & & 641 & $239.4(108.7)$ & \\
\hline Total & 5518 & $192.3(81.2)$ & & 10658 & $232.1(109.5)$ & \\
\hline
\end{tabular}

$S D=$ standard deviation . 
levels but lower mean random CPG levels than men $(P<0.001)$.

Blood pressure measurements showed that 14423 (46.9\%) patients had systolic blood pressure $<130$ $\mathrm{mmHg}, 8794$ (28.6\%) had diastolic blood pressure $<80 \mathrm{mmHg}$ and 6926 (22.5\%) had blood pressure within the range currently recommended by the American Diabetes Association (systolic $<130 \mathrm{mmHg}$ and diastolic $<80$ $\mathrm{mmHg}$ ).

\section{Relationship between glycaemic control and patients' characteristics}

The proportion of patients with controlled glycaemia was generally higher in the younger age groups (Table 2). More men that women had glycaemic control $(P<0.001)$. The highest rate of glycaemic control was found in patients managed at private health facilities and the lowest among those managed in multiple health care facilities, followed by those managed in $\mathrm{MOH}$ health care facilities $(P<0.001)$.

The highest rate of glycaemic control was recorded among patients whose marital status was single and those with professional employment, while the lowest was noted among the widowed and self-employed $(P<0.001)$ (Table 3$)$. The proportion of patients with controlled glycaemia increased as the level of education and income increased $(P<0.001)$.

Table 4 shows the distribution of glycaemic control in relation to geographic sectors of the Eastern province. The highest rate of glycaemic control was among patients in Khober and the lowest was in Qaria Olaya. Lower rates of glycaemic control were recorded in rural than in urban areas $[588(22.7 \%)$ versus $9795(34.8 \%)(P<0.001)]$.

\section{Risk factors for poor glycaemic control}

Table 5 shows the comorbidity risk factors for patients diagnosed with DM compared with the total screened participants. The most prevalent associated risk factors for previous diagnosis of DM were positive family history of DM (19.0\%), positive history of CVD (47.0\%), hypertension (41.0\%), obesity (19.4\%) and low physical activity (18.5\%), while those diagnosed with DM were less likely to be current smokers than subjects without a previous diagnosis of DM (12.1\%) $(P<0.001)$.

The distribution of glycaemic control in patients with previously diagnosed DM in relation to the same risk factors is shown in Table 6. Significantly more patients who were hypertensive had controlled CPG level than those who were pre-hypertensive or non-hypertensive. Regarding BMI, the highest rate of glycaemic control was among patients who were obese, followed by those who were overweight $(P<0.002)$. On the other hand, no significant association was observed in the rate of glycaemic control comparing those with and without a history of CVD or comparing current smokers with nonsmokers.

Multiple logistic regression analysis, with blood glucose control as the dependent variable, was performed to evaluate which factors were independently associated with glycaemic control in patients with diagnosed DM (Table 7). Increasing age was significantly associated with uncontrolled DM (OR $=1.02$; 95\% CI: 1.01-1.02, $P<0.001$ ),

\begin{tabular}{|c|c|c|c|c|c|c|}
\hline \multirow[t]{2}{*}{ Variable } & \multirow[t]{2}{*}{ Total no. } & \multicolumn{2}{|c|}{ Controlled glycaemia } & \multicolumn{2}{|c|}{ Uncontrolled glycaemia } & \multirow[t]{2}{*}{$P$-value } \\
\hline & & No. & $\%$ & No. & $\%$ & \\
\hline \multicolumn{7}{|l|}{ Age (years) } \\
\hline $30-39$ & 4697 & 1954 & 41.6 & 2743 & 58.4 & $<0.001$ \\
\hline $40-49$ & 9904 & 3433 & 34.7 & 6471 & 65.3 & \\
\hline $50-59$ & 8229 & 2594 & 31.5 & 5635 & 68.5 & \\
\hline $60-69$ & 5170 & 1541 & 29.8 & 3629 & 70.2 & \\
\hline $70+$ & 2547 & 801 & 31.4 & 1746 & 68.6 & \\
\hline $\operatorname{Sex}^{a}$ & & & & & & 0.022 \\
\hline Male & 14461 & 4980 & 34.4 & 9481 & 65.6 & \\
\hline Female & 16270 & 5401 & 33.2 & 10869 & 66.8 & \\
\hline \multicolumn{7}{|l|}{ Place offollow-up } \\
\hline MOH facility & 19192 & 5739 & 29.9 & 13483 & 70.1 & $<0.001$ \\
\hline $\begin{array}{l}\text { Other government } \\
\text { hospital }\end{array}$ & 5302 & 1983 & 37.4 & 3319 & 62.6 & \\
\hline Private facility & 3481 & 1439 & 41.3 & 2042 & 58.7 & \\
\hline Multiple places & 825 & 245 & 29.7 & 580 & 70.3 & \\
\hline
\end{tabular}

${ }^{a}$ Data missing for some patients.

$S D=$ standard deviation $; \mathrm{MOH}=$ Ministry of Health 


\begin{tabular}{|c|c|c|c|c|c|}
\hline \multirow[t]{2}{*}{ Variable } & \multirow[t]{2}{*}{ No. } & \multicolumn{2}{|c|}{$\begin{array}{l}\text { Controlled } \\
\text { glycaemia }\end{array}$} & \multicolumn{2}{|c|}{$\begin{array}{l}\text { Uncontrolled } \\
\text { glycaemia }\end{array}$} \\
\hline & & No. & $\%$ & No. & $\%$ \\
\hline \multicolumn{6}{|l|}{ Marital status ${ }^{* * *}$} \\
\hline Single & 468 & 209 & 43.0 & 277 & 57.0 \\
\hline Married & 26439 & 9009 & 34.1 & 17430 & 65.9 \\
\hline Widowed & 3004 & 915 & 30.5 & 2089 & 69.5 \\
\hline Divorced & 536 & 166 & 31.0 & 370 & 69.0 \\
\hline \multicolumn{6}{|l|}{ Occupation $^{* * *}$} \\
\hline Self-employed & 3029 & 924 & 30.5 & 2105 & 69.5 \\
\hline Housewife & 13964 & 4595 & 32.9 & 9369 & 67.1 \\
\hline Military & 1889 & 692 & 36.1 & 1207 & 63.9 \\
\hline Professional & 1722 & 687 & 39.8 & 1040 & 60.2 \\
\hline Technical & 924 & 358 & 38.7 & 566 & 61.3 \\
\hline Non-technical & 1036 & 306 & 29.6 & 730 & 70.5 \\
\hline Administrative & 3557 & 1392 & 39.1 & 2165 & 60.9 \\
\hline Unemployed & 3765 & 1173 & 31.2 & 2592 & 68.8 \\
\hline \multicolumn{6}{|l|}{ Education $* * *$} \\
\hline Illiterate & 13186 & 3807 & 28.9 & 9379 & 71.1 \\
\hline Read \& write & 3082 & 1007 & 32.7 & 2075 & 75.3 \\
\hline Primary & 4411 & 1534 & 34.8 & 2877 & 65.2 \\
\hline Intermediate & 3080 & 1174 & 38.1 & 1906 & 61.9 \\
\hline Secondary & 3810 & 1543 & 40.5 & 2267 & 59.5 \\
\hline University & 2218 & 987 & 44.5 & 1231 & 55.5 \\
\hline Higher degree & 182 & 90 & 49.5 & 92 & 50.5 \\
\hline \multicolumn{6}{|c|}{$\begin{array}{l}\text { Income (Saudi riyals } \\
\text { per month) }\end{array}$} \\
\hline$<2000$ & 7764 & 2367 & 30.5 & 5397 & 69.5 \\
\hline $2000-<5000$ & 7612 & 2411 & 31.7 & 5201 & 68.3 \\
\hline $5000-<7000$ & 4120 & 1455 & 35.3 & 2665 & 64.7 \\
\hline$>7000$ & 6083 & 2471 & 40.6 & 3612 & 59.4 \\
\hline
\end{tabular}

***P $<0.001$

and glycaemic control was also less common among patients who were current smokers (OR $=1.11$; 95\% CI: $1.02-1.20, P=0.018)$ or who had a sedentary level of physical activity. On the other hand, being hypertensive was positively associated with glycaemic control $(\mathrm{OR}=0.80$; 95\% CI: 0.76-0.85, $P<0.001)$.

Moderate or strenuous physical activity, sex, BMI, being pre-hypertensive or having a history of CVD did not show any significant association with glycaemic control. is suboptimal in most clinical settings [13-15]. In our study only one-third of diabetic patients achieved the recommended glycaemic level and less than one-quarter of them had blood pressure control. Data from the National Health and Nutrition Examination Survey in 1999-2000 showed that $35.8 \%$ of diabetics had achieved their glycaemic target, and 35.8\% had achieved the target blood pressure of $<130 / 80 \mathrm{mmHg}$ [16], which are better rates of control than in our study. This could be related to the inclusion of younger subjects (20 years and above) than in our study of over 30-year-olds.

The management of DM provides an excellent model for the quality of health care administered in different clinical settings and the health disparities in different regions, as illustrated by our finding that certain districts and rural populations experienced a disproportionate disease burden due to DM. This was also true for patients receiving management through $\mathrm{MOH}$ facilities than in other settings. Our study also provided a benchmark for quality of diabetes care across different groups, such as age, sex and socioeconomic subgroups.

The level of glycaemic control in our DM patients increased as their level of education and income increased. Populations of lower socioeconomic status have been shown to have a higher rate of diabetes-related complications and this has been attributed to a lower quality of care for these patients [15,17]. However, health care in Saudi Arabia is accessible to all and provided free of charge for the citizen population so the poor control of DM may be due to risk factors other than disparities in health care. Failure to achieve the glycaemic target in spite of the availability of efficacious treatment has been studied before, and is influenced by different factors related to the patient, provider and health care system and may be explained by a breakdown 


\begin{tabular}{lcccccc}
\hline $\begin{array}{l}\text { Table } 4 \text { Distribution of patients with controlled and uncontrolled glycaemia by health sectors (districts) of the Eastern } \\
\text { province }\end{array}$ & No. & Controlled glycaemia & Uncontrolled glycaemia & $P$-value \\
\hline Health sector & & No. & $\%$ & No. & $\%$ & $<0.001$ \\
& 4858 & 1869 & 38.5 & 2989 & 61.5 & 56.6 \\
Dammam & 4455 & 1935 & 43.4 & 2520 & 60.4 \\
Khober & 3210 & 1271 & 39.6 & 1939 & 68.0 \\
Qateif & 732 & 234 & 32.0 & 498 & 76.4 \\
Ras Tanura & 850 & 201 & 23.6 & 649 & 67.7 \\
Bqaiq & 600 & 194 & 32.3 & 406 & 58.3 \\
Safwa & 703 & 293 & 41.7 & 410 & 72.5 \\
Jubail & 538 & 148 & 27.5 & 390 & 78.8 \\
Khafji & 198 & 42 & 21.2 & 156 & 76.8 \\
Oraera & 634 & 147 & 23.2 & 487 & 77.1 \\
Nuaeria & 441 & 101 & 22.9 & 340 & 81.8 \\
Sarar & 296 & 54 & 18.2 & 242 & 75.6 \\
Qaria Olaya & 176 & 43 & 24.4 & 133 & 69.7 \\
Rafeia & 11177 & 3392 & 30.3 & 7785 & 75.4 \\
Al-Hassa & 1867 & 459 & 24.6 & 1408 & \\
Hafr-Albaten & & & &
\end{tabular}

\begin{tabular}{|c|c|c|c|c|}
\hline \multirow[t]{2}{*}{ Variable } & \multirow{2}{*}{$\begin{array}{c}\text { Total subjects } \\
\text { No. }\end{array}$} & \multicolumn{2}{|c|}{ Previously diagnosed DM } & \multirow[t]{2}{*}{$P$-value } \\
\hline & & No. & $\%$ & \\
\hline \multicolumn{5}{|l|}{ Family history of DM } \\
\hline Yes & 100109 & 19005 & 19.0 & \multirow[t]{2}{*}{$<0.001$} \\
\hline No & 96660 & 11793 & 12.2 & \\
\hline \multicolumn{5}{|c|}{ Personal history of CVD } \\
\hline Yes & 5372 & 2526 & 47.0 & \multirow[t]{2}{*}{$<0.001$} \\
\hline No & 191397 & 28272 & 14.8 & \\
\hline \multicolumn{5}{|l|}{ Blood pressure } \\
\hline Hypertensive & 30484 & 12492 & 41.0 & \multirow[t]{2}{*}{$<0.001$} \\
\hline Non-hypertensive & 166285 & 18306 & 11.0 & \\
\hline \multicolumn{5}{|l|}{ Tobacco smoking } \\
\hline Current smoker & 33065 & 4003 & 12.1 & \multirow[t]{2}{*}{$<0.001$} \\
\hline Nonsmoker & 163164 & 26677 & 16.3 & \\
\hline \multicolumn{5}{|l|}{ BMI } \\
\hline Underweight & 2617 & 120 & 4.6 & \multirow[t]{4}{*}{$<0.001$} \\
\hline Normal weight & 38651 & 3670 & 9.5 & \\
\hline Overweight & 68720 & 10219 & 14.9 & \\
\hline Obese & 85780 & 16633 & 19.4 & \\
\hline \multicolumn{5}{|l|}{ Physical activity } \\
\hline Sedentary & 50535 & 9372 & 18.5 & \multirow[t]{4}{*}{$<0.001$} \\
\hline Mild & 104382 & 16379 & 15.7 & \\
\hline Moderate & 35847 & 4384 & 12.2 & \\
\hline Strenuous & 4623 & 439 & 9.5 & \\
\hline
\end{tabular}

$C V D=$ cardiovascular disease $B M I=$ body mass index . 


\begin{tabular}{|c|c|c|c|c|c|c|}
\hline \multirow[t]{2}{*}{ Variable } & \multirow{2}{*}{$\begin{array}{c}\text { Total } \\
\text { No. }\end{array}$} & \multicolumn{2}{|c|}{ Controlled glycaemia } & \multicolumn{2}{|c|}{ Uncontrolled glycaemia } & \multirow[t]{2}{*}{$P$-value } \\
\hline & & No. & $\%$ & No. & $\%$ & \\
\hline \multicolumn{7}{|c|}{ Personal history of CVD } \\
\hline Yes & 2522 & 860 & 34.1 & 1662 & 65.9 & \multirow[t]{2}{*}{0.725} \\
\hline No & 28214 & 9524 & 33.8 & 860 & 66.2 & \\
\hline \multicolumn{7}{|l|}{ Blood pressure } \\
\hline Hypertensive & 12468 & 4455 & 35.7 & 8013 & 64.3 & \multirow[t]{3}{*}{$<0.001$} \\
\hline Pre-hypertensive & 527 & 158 & 30.0 & 369 & 70.0 & \\
\hline Non-hypertensive & 17738 & 5768 & 32.5 & 11970 & 67.5 & \\
\hline \multicolumn{7}{|l|}{ Tobacco smoking } \\
\hline Current smoker & 3997 & 1372 & 34.3 & 2625 & 65.7 & \multirow[t]{2}{*}{0.44} \\
\hline Nonsmoker & 26622 & 8972 & 33.7 & 17650 & 66.3 & \\
\hline \multicolumn{7}{|l|}{$B M I$} \\
\hline Underweight & 120 & 41 & 34.2 & 79 & 65.8 & \multirow[t]{4}{*}{0.002} \\
\hline Normal weight & 3660 & 1146 & 31.3 & 2514 & 68.7 & \\
\hline Overweight & 10198 & 3403 & 33.4 & 6795 & 66.6 & \\
\hline Obese & 16604 & 5740 & 34.6 & 10864 & 65.4 & \\
\hline \multicolumn{7}{|l|}{ Physical activity } \\
\hline Sedentary & 9360 & 3220 & 34.4 & 6140 & 65.5 & \multirow[t]{4}{*}{0.001} \\
\hline Mild & 16347 & 5379 & 32.9 & 10968 & 67.1 & \\
\hline Moderate & 4370 & 1525 & 34.9 & 2845 & 65.1 & \\
\hline Strenuous & 438 & 173 & 39.5 & 265 & 60.5 & \\
\hline
\end{tabular}

$C V D=$ cardiovascular disease $; B M I=$ body mass index .

of communication related to these 3 factors [18].

Substantial attention has been focused recently on the organizational and economic aspects of medical care for diabetic patients [19] and this is reflected by our findings which suggest that betterknowledge and motivation of patients plays a major part in glycaemic control and self-care practice of adults with DM. This has been highlighted by different organizations and shown to have major implications for health care policy $[9,20]$. A meta-analysis that reviewed the efficacy of diabetes education has found that approaches based on diet instruction and social learning were the most effective interventions for achieving glycaemic control $[21,22]$. Naik et al. stressed the importance of patients actively self-monitoring their blood glucose levels, and then communicating these results to their physician, who can then adjust the medication to reach the glycaemic targets [23].

In univariate analysis, obesity was associated with having glycaemic control, but regression analysis could not show a significant relationship between BMI and glycaemic control. The same was found by other researchers who attributed the anomaly to the type of crosssectional study in which patients with good glycaemic control gain weight and patients with poor glycaemic control lose weight due to the disease process [15]. Our explanation is that this may be due to the greater concern of obese individuals to control their glycaemic level.

Good blood pressure control is a central outcome of high-quality diabetes care. The JNC VII report in 2003 recommended that blood pressure be reduced to less than $130 / 80 \mathrm{mmHg}$ [11], due to consistent evidence that intensive control of blood pressure in adults with type $2 \mathrm{DM}$ prevents both microvascular and macrovascular diseases [24,25]. Clinical trials indicated that reducing blood pressure by 10 $\mathrm{mmHg}$ would decrease macrovascular and microvascular complications and mortality rates by $35 \%$ [25]. Our findings revealed that individuals with DM have better control of hypertension, and this may reflect more concern and care among groups at risk than others.

The key finding of this study - that the overall rate of diabetes control in Eastern province of Saudi Arabia is unacceptably low in the general population-has important implications. Improving health care disparities in glycaemic control should be a public health priority in order to reduce diabetes-related morbidity and mortality in the community. Patients need to be empowered with the knowledge and resources to enhance their individual par- 


\begin{tabular}{|c|c|c|c|c|}
\hline Variable & $\begin{array}{l}\text { Logistic } \\
\text { regression } \\
\text { coefficient }\end{array}$ & $\begin{array}{l}\text { Odds } \\
\text { ratio }\end{array}$ & $95 \% \mathrm{Cl}$ & $P$-value \\
\hline Age & 0.015 & 1.00 & $1.01-1.02$ & $<0.001$ \\
\hline \multicolumn{5}{|l|}{ Sex } \\
\hline Women & & 1 & & \\
\hline Men & -0.10 & 0.99 & 0.93-1.05 & 0.750 \\
\hline Personal history of CVD & 0.024 & 1.02 & $0.93-1.14$ & 0.644 \\
\hline \multicolumn{5}{|l|}{ Blood pressure } \\
\hline Normal & & 1 & & $<0.001$ \\
\hline Hypertensive & -0.220 & 0.80 & $0.76-0.85$ & $<0.001$ \\
\hline Pre-hypertensive & 0.180 & 1.20 & $0.94-1.52$ & 0.137 \\
\hline \multicolumn{5}{|l|}{ Tobacco smoking } \\
\hline \multicolumn{5}{|l|}{ Current smoker } \\
\hline Nonsmoker & 0.10 & 1.11 & $1.02-1.20$ & 0.018 \\
\hline \multicolumn{5}{|l|}{$B M I$} \\
\hline Underweight & & 1 & & 0.078 \\
\hline Normal weight & 0.118 & 1.13 & $0.71-1.79$ & 0.618 \\
\hline Overweight & -0.005 & 1.00 & $0.63-1.58$ & 0.983 \\
\hline Obese & 0.003 & 1.00 & $0.63-1.59$ & 0.989 \\
\hline \multicolumn{5}{|l|}{ Physical activity } \\
\hline Sedentary & & 1 & & 0.011 \\
\hline Mild & 0.078 & 1.08 & $1.02-1.15$ & 0.14 \\
\hline Moderate & -0.005 & 1.00 & $0.91-1.09$ & 0.920 \\
\hline Strenuous & -0.162 & 0.85 & $0.68-1.06$ & 0.148 \\
\hline
\end{tabular}

$C V D=$ cardiovascular disease $; \mathrm{MI}=$ body mass index $\mathrm{Cl}=$ confidence interval. ticipation in diabetes self-care in order to improve their glycaemic control.

There were some limitations to this study. Details about management regimens and the duration of diagnosed diabetes were not known. HbAlc, which is a strong indicator of glycaemic control and which would give us a more comprehensive picture, was not measured. However, this study had its strengths, including the large sample size. Subjects with undiagnosed DM were excluded from this study, as they were not aware of their disease status and were not in a position to control their blood glucose and related cardiovascular risks. Finally, we reported the distribution of random $C B G$, fasting CBG level and blood pressure on the basis of clinical examination and not on records.

\section{Acknowledgements}

We thank all who participated in the campaign for their enthusiasm in fulfilling the study objectives.

\section{References}

1. Bloomgarden Z. The epidemiology of complications. Diabetes care, 2002, 25:924-32.

2. Effect of intensive blood-glucose control with metformin on complications in overweight patients with type 2 diabetes (UKPDS 34). UK Prospective Diabetes Study (UKPDS) Group. Lancet, 1998, 352:854-65.

3. Intensive blood-glucose control with sulphonylureas or insulin compared with conventional treatment and risk of complications in patients with type 2 diabetes (UKPDS 33). UK Prospective Diabetes Study (UKPDS) Group. Lancet, 1998, 352:837-53.

4. Ohkubo $\mathrm{Y}$ et al. Intensive insulin therapy prevents the progression of diabetic microvascular complications in Japanese patients with non-insulin-dependent diabetes mellitus: a randomized prospective 6-year study. Diabetes research and clinical practice, 1995, 28:103-17.

5. Selvin E et al. Meta-analysis: glycosylated hemoglobin and cardiovascular disease in diabetes mellitus. Annals of internal medicine, 2004, 141:421-31.

6. Eastman RC et al. Model of complications of NIDDM. II. Analysis of the health benefits and cost-effectiveness of treating NIDDM with the goal of normoglycemia. Diabetes care, 1997, 20:735-44

7. Eastman RC et al. Model of complications of NIDDM. I. Mode construction and assumptions. Diabetes care, 1997, 20:725-34.
8. Stratton IM et al. Association of glycaemia with macrovascular and microvascular complications of type 2 diabetes (UKPDS 35): prospective observational study. British medical journal, 2000, 321:405-12.

9. American Diabetes Association. Standards of medical care in diabetes-2008. Diabetes care, 2008, 31(Suppl. 1):S12-54.

10. Al-Ghamdi A et al. A community-based screening campaign for the detection of diabetes mellitus and hypertension in the eastern province, Saudi Arabia: methods and participation rate. Journal of family and community medicine, 2007, 14(3):91-7.

11. Chobanian AV et al. Seventh report of the Joint National Committee on Prevention, Detection, Evaluation, and Treatment of High Blood Pressure. Hypertension, 2003, 42:1206-52.

12. The Diabetes Control and Complications Trial Research Group. The effect of intensive treatment of diabetes on the development and progression of long-term complications in insulin-dependent diabetes mellitus. New England journal of medicine, 1993, 329:977-86.

13. Brechner RJ et al. Ophthalmic examination among adults with diagnosed diabetes mellitus. Journal of the American Medical Association, 1993, 270:1714-8.

14. Beckles GL et al. Population-based assessment of the level of care among adults with diabetes in the US. Diabetes care, 1998, 21:1432-8. 
15. Harris MI et al. Racial and ethnic differences in glycemic control of adults with type 2 diabetes. Diabetes care, 1999, 22:403-8.

16. Saydah SH, Fradkin J, Cowie CC. Poor control of risk factors for vascular disease among adults with previously diagnosed diabetes. Journal of the American Medical Association, 2004, 291:335-42.

17. Peek ME, Cargill A, Huang ES. Diabetes health disparities: a systematic review of health care interventions. Medical care research and review, 2007, 64(5 Suppl.):101S-56S.

18. Pringle $\mathrm{M}$ et al. Influences on control in diabetes mellitus: patient, doctor, practice, or delivery of care? British medical journal, 1993, 306:630-4.

19. Bransome ED Jr. Financing the care of diabetes mellitus in the U.S. Background, problems, and challenges. Diabetes care, 1992, 15(Suppl. 1):1-5.

20. Norris SL, Engelgau MM, Narayan KM. Effectiveness of selfmanagement training in type 2 diabetes: a systematic review of randomized controlled trials. Diabetes care, 2001, 24:561-87.
21. Padgett D et al. Meta-analysis of the effects of educational and psychosocial interventions on management of diabetes mellitus. Journal of clinical epidemiology, 1988, 41:1007-30.

22. Norris SL et al. Self-management education for adults with type 2 diabetes: a meta-analysis of the effect on glycemic control. Diabetes care, 2002, 25:1159-71.

23. Naik AD et al. Improving hypertension control in diabetes mellitus: the effects of collaborative and proactive health communication. Circulation, 2008, 117:1361-8.

24. Cooper $\mathrm{ME}$, Johnston $\mathrm{Cl}$. Optimizing treatment of hypertension in patients with diabetes. Journal of the American Medical Association, 2000, 283:3177-9.

25. Tight blood pressure control and risk of macrovascular and microvascular complications in type 2 diabetes: UKPDS 38. UK Prospective Diabetes Study Group. British medical journal, 1998, 317:703-13.

\section{Second Annual Meeting of the Global Diabetes Alliance (GDA 2), Cairo, Egypt, 26-29 October, 2010}

Cairo will host the second Global Diabetes Alliance Congress, a very special event whose goal is to unify protocols for epidemiological surveys and prevention and management of diabetes and its related disorders. This Congress will be dedicated to the presentation of updates on the diabetes epidemic in various parts of the world (including the Middle East and Africa) and workshops designed to initiate collaborative research projects among groups of investigators throughout the world. The programme can be accessed from the conference website at: http://conf.global-diabetes.org/index.htm 